\title{
AJARAN TATTWA DAN ETIKA DALAM LONTAR TUTUR PARAKRIYA
}

\author{
Oleh : I Made Pasek Subawa
}

\begin{abstract}
The teaching of tattwa is a divine philosophy that is a thought of spiritual values that can strengthen human beliefs on god's omnipotence in life. The teachings are widely poured into various papers contained in the speeches that are the result of the deep (kawia) thought of an author. One of them is in the parachute talk. This lontar says much about the teachings of tattwa who teach about escape or moksa as a unification of àtma and brahman (god). In addition to the teachings of the moksa, there are also ethical teachings that are poured into chess paramita as the four main attributes or attitudes that become the basis or basic concept in doing daily acts. So in this parachute speech, it becomes a reflection of the teachings of divine philosophy and the ethical values that can be used in the guidance or holding the teachings of Hinduism.
\end{abstract}

Keywords: Tattwa, Ethics, Lectar, Parakriya.

\section{Pendahuluan}

Lontar Tutur Parakriya adalah karya sastra klasik turunan lontar asli Ida Pedanda Keniten dari Tampaksiring (Gianyar), dan disalin ke dalam lontar sesuai aslinya oleh I Ketut Kaler dari Br. Paketan, Singaraja serta dikoleksi oleh Museum Gedong Kirtya, Singaraja pada tanggal 14 Mei 1929 dengan jumlah lampiran terdiri dari duapuluh lembar, panjang $50 \mathrm{~cm}$ dan lebar 3,5 cm dengan No. III B. 601/1, dimana III B merupakan kode tempat, 601 adalah jenis lontar dan 1 adalah nomor keropak. Lontar Tutur Parakriya menguraikan tentang percakapan antara Bhatara Iswara kepada Sang Hyang Kumara. Diawali permintaan dari Bhatari Uma agar Sang Hyang Kumara berkenan menanyakan kepada Bhatara Iswara tentang ajaran yang mengantarkan sesorang menuju moksa. Selanjutnya Sang Hyang Kumara bertanya mengenai asal mula kejadian yang dinyatakan bahwa segala sesuatu yang ada berasal dari Ida Sang Hyang Widhi/ Tuhan Yang Maha Esa yang diistilahkan dengan niskala. Dari keadaan niskala kemudian timbul sesuatu yang berwujud namun tanpa ukuran sehingga disebut matra. Dari matra tersebut kemudian menyusul berturut-turut nadha, windu dan ardhacandra yang kemudian menimbulkan pusat keadaan yang disebut dengan wiswa. Selanjutnya dari wiswa muncul 
aksara yang meliputi konsep-konsep Triaksara, Pancabrahma dan Pancaksara. Aksara bersangkutan meliputi suara dan wyanjana yang merupakan perwujudan dari para dewata. Dengan perwujudan dewata seperti itu, maka kepada para pendeta dianjurkan agar dalam pemujaan senantiasa dilengkapi dengan sarana kesucian yang terdiri dari bunga, biji, beras, dupa, lampu dan air cendana. Penggunaan perlengkapan tersebut sejalan dengan pengertian tentang kesucian wujud Ida Sang Hyang Widhi Wasa/ Tuhan Yang Maha Esa yang dinyatakan dalam berbagai media diantaranya adalah dalam ongkara. Perwujudan Tuhan dalam hubungan lain terdapat dalam hubungan antara dewa dengan arah mata angin.

Dikatakan bahwa sesungguhnya jalan menuju kebebasan abadi yang disebut dengan "marganing anemu kamoksan" adalah pemutaran aksara yang utama sebagai sasaran yoga dalam wujud Ongkara. Yang dapat dijabarkan kedalam Triaksara, selanjutnya kepada Pancaksara dan segala macam aksara keramat. Dengan bagian keramatnya pada nadha, windhu, dan ardhacandra sebagai tujuan dari pemusatan pikiran. Pemusatan pikiran akan tercapai dengan sempurna melalui tehnik pemejaman mata, karena dengan demikian akan tampak sinar yang sangat suci dan kesunyian. Di samping itu disebutkan pula mantra-mantra seperti mantra Pancawara, Sadwara, Saptawara. Hidup ini tidak kekal, lahir dan tumbuh di tanah yang kembali kepada air, kemudian kepada sinar, selanjutnya kepada angin, yang akhirnya kepada angkasa. Pernyataan tersebut dilandasi dengan pengertian tentang adanya persatuan antara tubuh dengan dewa sebagai lambang persatuan kosmos, antara lain: Saptaloka, Sapta Patala, Sapta Dwipa (bhumi), Saptaparwata, Sapta Tirtha. Selanjutnya dalam rumusan tenaga kehidupan disebutkan: pada pangkal jantung berada Dewa Isa yang menimbulkan sifat toleransi, pada bagian tengah jantung berada Dewa Dharma yang menimbulka sifat suka bersahabat, pada mulut berada Dewa Iswara yang menimbulkan sifat kasih sayang, bahan makanan Dewa Brahma yang menimbulkan semangat hidup, pada bahan rasa berada Dewa Wisnu yang menimbulkan sifat prilaku, pada bahan tenaga berada Dewa Mahadewa yang menimbulkan sifat simpati.

Mengenai Panca Maha Bhuta yang dihubungkan dengan tubuh manusia disebutkan: Pertiwi menjadi daging, Apah menjadi darah, Teja menjadi sinar, Bayu menjadi nafas, Akasa menjadi dwara. Ada juga rumusan Panca Bayu yaitu Bayu Prana, Bayu Apana, Bayu Udana, Bayu Biana, tentang Sapta Pada, Tri Anta Karana, Tri Loka. Dewanya Tri Guna disebutkan: Dewa Rudra sebagai rajah, Dewa Sangkara sebagai tamah, Mahadewa sebagai sattwam. Bagian Bhuana Sangsipta disebutkan bahwa itulah merupakan jalan menuju kelepasan bagi seorang Yogiswara. Jika sudah memahami tentang isi dan sifatnya maka setidak-tidaknya tentu akan mencapai sorga. Ditegaskan sekali bahwa seorang Yogiswara hendaknya memahami kesadaran diri melalui ajaran falsafah karena ia merupakan jalan untuk mencapai sorga. Naskah Tutur Parakriya ditutup dengan sebuah mantra pamandiswara yang mana Bhatara Siwa adalah sarinya dunia semua, sebagai penguasa dunia dan sebuah percakapan tentang kewajiban seorang pendeta yang sejati, yang senantiasa mengusahakan 
kesadaran diri. Jika tidak demikian maka tidak berbeda halnya dengan Dukuh Dekih. Demikian ajaran tentang Arsa Timbangan dituangkan dalam perakapan antara Dukuh Alon dengan Dukuh Wisesa.

\section{Pembahasan}

\subsection{Ajaran Tattwa dalam Lontar Tutur Parakriya}

Salah satu ajaran tattwa atau filsafat Agama Hindu yang dipaparkan dalam Lontar Tutur Parakriya menekankan pada ajaran Moksa, yang merupakan salah satu dari sradha atau keyakinan dalam ajaran Agama Hindu. Kebahagiaan yang sejati akan tercapai oleh sesorang, apabila telah dapat menyatukan jiwanya dengan Ida Sang Hyang Widhi/ Tuhan Yang Maha Esa. Penyatuan dengan Tuhan itu baru akan didapat apabila telah melepaskan semua bentuk ikatan pada dirinya. Kata Moksa berasal dari bahasa Sansekerta, yaitu dari akar kata Muc yang berarti membebaskan atau melepaskan. Dengan demikian, kata Moksa berarti kelepasan dan kebebasan. Dari segi istilah, Moksa disamakan dengan nirwana dan nisreyasa atau keparamarthan. Adapun ajaran tattwa dalam Lontar Tutur Parakriya, adalah sebagai berikut :

Batari Uma mawuwus; Pradana sastra kabeh tan ana mungguh nira ring aji. Ndan dana tang nistayoga nga. Wenang tamtamana mangdadiaken kamoksan; ya tika tapwan awruhnira tinakwan anaknira Bhatara Iswara. Rowangnira atekwan Sang Hyang Kumara, ndan sahapancopacarasara, ikang ling nira patakwan ring Batara.(Transkripsi Lontar Tutur Parakriya, lampiran 1b).

\section{Terjemahan:}

Bhatari Uma berkata; yang disebut pradana sastra semua itu tidak terdapat di dalam ajaran (agama). Yang ada hanya Nista Yoga namanya, itu patut dipelajari untuk menuju kemoksaan. Hal itu tidak di ketahuinya itu yang ditanyakan kepada Bhatara Iswara. Yang menyertai bertanya adalah Sang Kumara, lengkap dengan tatacara/ upacara untuk menanyakan. Katanya bertanya kehadapan Bhatara.

Berdasarkan kutipan di atas menjelaskan bahwa yang disebut dengan Predana Sastra tidak terdapat dalam ajaran (agama), yang ada hanya Nista Yoga yang patut dipelajari sebagai jalan atau cara untuk menuju pada kebenaran yang hakiki, yaitu moksa. Dengan mengetahui ajaran-ajaran sebagai jalan untuk menuju moksa, maka pikiran dipusatkan pada kesucian, agar nantinya dapat tercapai tujuan yang hendak diinginkan. Sehubungan dengan hal tersebut, Lontar Tutur Parakriya menyebutkan sebagai berikut :

ikang jnyana kabeh lawan tatwa, Bhatara majaraken ndia ikanang nirbana-pada wekasning jnyana, suksmaning suksma ya, acin titing, tan kaucap dening ulun. (Transkripsi Lontar Tutur Parakriya, lampiran 12a).

\section{Terjemahan:}

Itu jnyana dan tattwa, paduka Bhatara menyebutkan yang mana disebut nirbanapada, terakhirnya jnyana, yang sangat gaib dan suci nirmala tak terpikirkan oleh hamba 
Maksud kutipan di atas menjelaskan tentang pengetahuan yang benar dan sejati yang sangat suci untuk menuju kepada kenirbanaan, apabila tidak memiliki pengetahuan yang mulia, tentunya tidak akan menemui tujuan yang disebut nirwana. Agar moksa dan nirwana itu dapat tercapai maka harus terlebih dahulu lahir menjadi manusia, dengan lahir menjadi manusia adalah merupakan pintu gerbangnya moksa, karena dewapun akan lahir menjadi manusia untuk dapat meningkatkan diri agar bisa mencapai moksa. Moksa berarti kebebasan atau kelepasan, maksudnya suatu kebahagiaan dimana atma dapat lepas dari pengaruh maya dan ikatan Śubhāśubhakarma serta bersatu kembali dengan asalnya yaitu Brahman (Tuhan). Atma (roh) tidak mengulangi kelahiran kembali, artinya bebas dari reinkarnasi dan mencapai kebahagiaan sejati dan abadi, sukha tan pawali dukha. (Titib, 1994: 73). Sebenarnya manusia dengan attmanya itu pernah bersatu dengan Brahman dan pernah merasakan kenikmatan dari sukha tan pawali duhka. Dengan kridanya Brahman, maka manusia itu terlempar lagi kegelombangnya maya. Di dalam maya segala kebahagiaan dan kesukaan itu selalu disertai dengan kedukaan atau dimana ada kesukaan tentu ada penderitaan yang mengikutinya. Jadi atma itu selalu rindu dan ingin kembali pada asalnya yaitu Tuhan, seperti halnya titik-titik air laut yang menjadi embun kemudian jatuh menjadi hujan serta mengalir ke sungai melaju dengan derasnya karena rindu bertemu lagi dengan sumbernya.

Adapun disebutkan dalam Lontar Tutur Parakriya, mengenai pikiran-pikiran yang mengarah pada kesucian (kesadaran berpikir) disebutkan sebagai berikut:
Kalingania ikang cita tania cetana ika, sadanitia karma, ya ta adnyana sunia nga (Lontar Tutur Parakriya, lampiran 12b).

\section{Terjemahannya:}

Sebenarnya pikiran tania cetana itu, selalu bekerja, itu yang disebut dengan adnyana sunia.

Berdasarkan kutipan Lontar Tutur Parakriya lampiran 12b tersebut, menjelaskan pengetahuan atau kesadaran pikiran itu selalu bekerja atau melakukan sesuatu untuk mengosongkan pikiran untuk menuju pada kebenaran yang sejati (Moksa). Sehubungan dengan uraian tersebut, Sarasamuscaya menyebutkan sebagai berikut :

Apa ika sang telas tumemung kaprajñān, kalangka pwa jñānanira, katemu tang, hilang kalanganing jñānanira, nis sattwaguna denira, sattwa kewala, tan karaketan, rajah tamah, sattwa ngaraning satah bhāwah, si uttamajñāna, citta zat swabhāwa, tar kakenan, trsnadi, katemu pwang sattwaguna denira, prasannātmakata sira, tan karaket ring sarīra, luput ring karmaphala. (Sarasamuscaya, 507).

\section{Terjemahan:}

Karena orang yang telah mendapatkan kebijaksanaan, lenyap segala noda pikirannya, tanpa noda ilmunya, maka sifat "sattwa" diprolehnya, sifat sattwa saja, tidak dak dipengaruhi oleh sifat "rajah tamah", sattwa artinya sifat baik, yaitu ilmu yang utama. Hakekat pikiran yang baik, tidak terpengaruh oleh trsna dan sejenisnya; didapati sifat sattwa olehnya, 
maka ia berjiwa suci bersih, tidak terikat pada badannya, bebas dari karmaphala. (Kadjeng, 1997: 393).

Kutipan di atas menjelaskan orang yang telah mendapat kebijaksanaan atau kesadaran dalam berpikir, lenyaplah akan segala noda pikirannya, tanpa noda ilmunya, maka sifat sattwa diperolehnya mereka itu diperolehnya yang merupakan hakekat pikiran yang baik dan tidak berpengaruh oleh keterikatan maya, maka ia berjiwa suci dan bebas dari karmaphala. Moksa dapat dicapai di dunia ini (ketika masih hidup) dan dapat pula dicapai setelah hidup ini berakhir. Orang yang dapat membebaskan dirinya (pikiran dan inderal kama) dari ikatan keduniawian dan pengaruh suka duka yang muncul dari Tri Guna akan dapat mencapai kelepasan itu, sebagaimana Bhagawadgita, XIV.9 menjelaskan sebagai berikut:

Sattvaim sukhe sañjayati

rajah karmaṇi bhārata

jñ̄anam āvrtya tu tamah

pramāde sañjayaty uta

\section{Terjemahan:}

Sattva mengikat sesorang pada kebahagiaan, rajah pada kegiatan kerja, wahai Bharata, sementara tamah menyelubungi pengetahuan dan mengikat kita pada kekurangwaspadaan (Pudja, 1999: 346).

Yadā sattve pravrddhe

Tu Pralayam yāti deha-bhrt

Tadottama-vidām lokān

Amalān pratipadyate.

(Bhagawadgita XIV.14).

\section{Terjemahan:}

Tetapi bila sattva bertambah pada saat menemui ajal, para arif mengetahui perginya ke alam tertinggi yang tanpa cela (Pudja, 1999: 349).

Pembebasan diri dari pengaruh Tri Guna adalah usaha yang berat, tetapi pasti dapat dilakukan dengan mendasarkan diri pada disiplin. Renungkan sloka di atas bila seseorang ingin mencapai moksa. Secara filosofis kebebasan itu tidak pernah hilang tetapi oleh karena manusia hanyut oleh gelombangnya maya, dan dari kecil sudah dibius oleh kenyataan illusi sehingga terikat oleh khayalan. Padahal kalau dia sadar pada waktu itu sudah bebas. Adapun ketidaksadaran itu adalah karena kurang tahunya (absence of knowledge). Kalau seorang sudah sadar, dia akan tahu yang mana riil (nyata dan benar) dan yang mana bersifat maya/ illusi.

Berdasarkan penjelasan di atas, manusia mampu membedakan mana yang benar dan mana yang salah. Dengan kemampuannya manusia itu dapat meningkatkan taraf hidup dan kehidupannya baik lahir maupun bathin, Lontar Tutur Parakriya menyebutkan sebagai berikut :

Ika Sang Rsi winarah de Batara irikang jnyanasti, ya ta matangian kapangguh ikang kamoksan denira, mari masarira. Wenang yan tininggalaken boga kabeh, dumeh nihan mangkana, sangkania asih Bhatara. (Transkripsi Lontar Tutur Parakriya, lampiran 13a).

\section{Terjemahan:}

Itu sang pendeta diajar oleh bhatara tentang jnyanasti, itu makanya beliau mencapai 
kemoksan, tidak masih berbadan, bisa beliau meninggalkan kehidupan semua, apa sebabnya demikian, memang dari karunia Ida Sang Hyang Widhi Wasal Tuhan Yang Maha Esa kepadanya yang menyebabkan.

Kutipan di atas menjelaskan khususnya bagi para $R s i$ atau yang mempunyai pengetahuan akan kesucian atau kebenaran yang tinggi tentunya untuk menghubungkan diri dengan Ida Sang Hyang Widhi Wasal Tuhan Yang Maha Esa yaitu melalui jalan pemusatan pikiran atau melalui samadhi yang dapat meninggalkan kehidupan semua untuk tercapainya suatu kemanunggalan. Mencapai kemanunggalan ini orang harus selalu berbuat baik sesuai dengan ajaran agamanya. Kitab suci telah menyediakan bagaimana caranya orang melaksanakan pelepasan dirinya dari ikatan maya dan akhirnya $\bar{A}$ tman dapat bersatu dengan Brahman, sehingga penderitaan dapat dikikis habis dan tidak lagi menjelma ke dunia sebagai hukuman, tetapi sebagai penolong sesama manusia.

Ajaran Agama Hindu terdapat jalan untuk mencapai kesempurnaan, yaitu Moksa, dengan menghubungkan diri dan pemusatan pikiran kepada Ida Sang Hyang Widhi Wasa yang disebut Catur Marga Yoga, yaitu: 1) Bhakti Marga Yoga, yaitu proses atau cara mempersatukan Atman dengan Brahman dengan berlandaskan atas dasar cinta kasih yang mendalam kepada Ida Sang Hyang Widhi Wasal Tuhan Yang Maha Esa, 2) Karma Marga Yoga adalah jalan atau usaha untuk mencapai kesempurnaan atau moksa dengan perbuatan atau kebajikan tanpa pamrih, 3) Jnana Marga Yoga mempersatukan jiwatman dengan paramatman yang dicapai dengan jalan mempelajari ilmu pengetahuan dan filsafat pembebasan diri dari ikatan-ikatan keduniawian, 4) Raja Marga Yoga adalah suatu jalan mistik (rohani) untuk mencapai kelepasan atau moksa dengan tiga jalan pelaksanaan yaitu Tapa Brata, Yoga, Samadhi. Tapa dan Brata merupakan suatu latihan untuk mengendalikan emosi atau nafsu yang ada dalam diri ke arah yang positif sesuai dengan petunjuk kitab suci sedangkan Yoga dan Samadhi adalah latihan untuk dapat menyatukan Atman dengan Brahman dengan melakukan meditasi atau pemusatan pikiran.

Berdasarkan penjelasan di atas, bahwa pemusatan pikiran itu memang penting untuk menghubungkan diri dengan Ida Sang Hyang Widhi Wasal Tuhan Yang Maha Esa, Lontar Tutur Parakriya menyebutkan sebagai berikut:

Wruh pwa Sang Yogiswara ring jnyana tatwa, ya marganing anemuwaken kamoksan. Mangkana palaning pangwruhaken ring swa tatwa, wenang mangdadiaken swarga kamoksanan. (Transkripsi Lontar Tutur Parakriya, lampiran 18a).

\section{Terjemahan:}

Sang Yogiswara patut mengetahui tentang keadaan dan isi dari jnyana tattwa sebab itu satu-satunya jalan untuk mencapai moksa. Demikianlah phalanya jika telah mengetahui dengan segala tattwa (ilmu) untuk mencapai kemoksan

Berdasarkan kutipan di atas menjelaskan bahwa Sang Yogiswara harus mengetahui tentang keadaan dan isi tattwa atau 
pengetahuan-pengetahuan, dengan mengetahui pengetahuan-pengetahuan (tattwa) itu merupakan satu-satunya jalan untuk tercapainya suatu tujuan yang paling hakiki (kenirwanaan) yang merupakan kemanunggalan Ätma dengan Brahman. Penghayatan dan pengamalan semua bentuk ajaran agama dalam hidup ini merupakan pelaksanaan kongkrit dari sabda Tuhan yang ada dalam pustaka suci. Lakukan pemujaan dan kerja sebagaimana mestinya sebagai bhakti kita kepada Ida Sang Hyang Widhi Wasal Tuhan Yang Maha Esa. Tanamkan keyakinan pada diri bahwa segala sesuatu berawal dan berakhir pada Tuhan. Segala sesuatu tidak mungkin akan terjadi tanpa Tuhan ikut di dalamnya. Semua makhluk akan dapat mencapai moksa, hanya jalan atau prosesnya berbeda, ada yang cepat dan ada yang pula yang lambat.

\subsection{Ajaran Etika dalam Lontar Tutur Parakriya}

Etika atau yang lebih dikenal dengan istilah "susila" dalam ajaran Agama Hindu berasal dari dua suku kata yakni su dan sila. Su artinya baik dan sila berarti kebiasaan atau tingkah laku perbuatan manusia yang baik. Karena itu dalam Agama Hindu, etika dikatakan sebagai ilmu yang mempelajari tata nilai, tentang baik dan buruk suatu perbuatan, apa yang harus dikerjakan atau harus dihindari, sehingga tercipta suatu hubungan baik diantara sesama manusia. Etika itu sendiri adalah tata laku atau perbuatan yang baik yang biasanya disebut sila. Ilmunya dinamakan ilmu tentang sila atau tata susila. Salah satu aspek dalam ilmu etika adalah membahas aspek moral dan arti dari apa yang dikatakan baik dan tidak baik. Etika adalah rasa cinta, rasa kasih sayang, dimana seseorang yang menerima etika itu adalah karena ia mencintai dirinya sendiri dan menghargai orang lain. Hal seperti itu rasa kebersamaan, rasa harga diri, ikut menentukan penyebarluasan dan pendalaman ajaran etika itu. Apa yang dipelajari dari Etika Hindu, ajaran etikanya pada dasarnya bertujuan meningkatkan derajat manusia dari tingkat yang lebih rendah, ketingkat yang lebih tinggi. Proses peningkatan itu tidak dapat terjadi tanpa mengalami proses pentahapan sehingga tampak adanya satu proses-proses peningkatan bertahap atau berjenjang sampai mencapai tingkat tujuan yang tertinggi, yaitu Moksa.

Oleh karena proses itu tidak hanya bersifat rasional, tetapi Etika Hindu mengandung arti kata bersifat mistik dan moral keagamaan sebagai prinsip dasar dalam ajaran sila itu menurut Agama Hindu adalah agar Sang Hyang Átma dapat mencapai moksa. Jadi pada pokoknya adalah sebagai ajaran dalam menuntun Ātma mencapai tingkat Paramatmal moksa, sesuai dengan tujuan ajaran Agama Hindu yang tertinggi. Etik Agama Hindu bertolak dari norma agama maka ia tidak sekedar etika penampilan luar sebagai etiket saja, namun ia menuntun orang untuk berbudi kerti yang luhur dan mulia sehingga tercapainya hidup yang berbahagia aman serta sentosa serta hubungan yang harmonis lahir bathin antara manusia dengan sesama makhluk lingkungannya, hubungan serasi antara manusia dengan Ida Sang Hyang Widhi Wasal Tuhan Yang Maha Esa.

Salah satu ajaran etika atau susila Agama Hindu yang mendasar dipaparkan dalam Lontar Tutur Parakriya menekankan pada ajaran Catur Pāramitha sebagaimana dijelaskan pada kutipan sebagai berikut: 
Mulaning pusuh-pusuh, Isa Hiangnia; Mudita wetunia; ring tengah, Dharma Hiangnia; Metri wetunia; ring tutuk, Iswara Hiangnia; Karuna wetunia. Iti ana wahanadi, Brahma Hiangnia, panasning ambek wetunia. Ikang rasa wahanadi, Wisnu Hiangnia, ing ambek wetunia. Ikang prana wahanadi, Mahadewa Hiangnia, Upeksa wetunia. Nahan Dewatania kamung Kumara. (Transkripsi Lontar Tutur Parakriya, lampiran 15b-16a).

\section{Terjemahan:}

Pertamanya atau puncaknya pepusuh, Hyang Isa dewatanya melahirkan Mudita; di tengah-tengah Hyang Dharma dewatanya menimbulkan Maitri. Penghabisannya Hyang Iswara, dewatanya menimbulkan Karuna. Ini ada disebut Wahanadi atau kendaraan utama, Brahma dewatanya, menimbulkan panas pikiran. Yang disebut rasa wahanadi, Wisnu dewatanya menimbulkan pemikiran. Yang disebut dengan prana wahanadi, Mahadewa dewatanya menimbulkan Upeksa (waspada) kamu Kumara.

Kutipan di atas menjelaskan bahwa jantung Hyang Isa dewanya menimbulkan Mudita, di tengah Hyang Darma dewatanya menimbulkan Maitri, terakhir Hyang Iswara dewatanya menimbulkan panas pikiran, rasa Wahana dan Wisnu dewanya menimbulkan pemikiran, Prana Wahanadi Mahadewa dewanya menimbulakan Upeksa. Dengan pemikiran cinta kasihlah yang menyebabkan dunia ini bergerak menuju kedamaian dan ketenangan. Manusia harus berbuat, berkata-kata dan berpikir yang baik dan benar, sesuai dengan ketentuan yang sudah berlaku dalam ajaran agama. Baik diperbuat maka hasilnya akan baik pula dan begitu sebaliknya jika berbuat yang jelek atau salah maka hasilnya akan jelek pula diterimanya. Sehubungan dengan uraian di atas maka dalam Lontar Tutur Parakriya, menyebutkan mengenai larangan yang harus direnungkan sekaligus dikerjakannya adalah sebagai berikut :

Ikanang sahalambana umidem, wastu tan ana ikang pada; nira lambana umidem, wastu ana tambana; ikang kamangkana rwa, ya teka aryakena denta. (Transkripsi Lontar Tutur Parakriya, 13a).

\section{Terjemahan:}

Jika sahalambana direnungkan, lalu tidak akan ada pada; jika niralambana dipikirkan lalu akan ada yang disebut dengan tambana, yang keduanya itu tidak patut dikerjakan olehmu.

Berdasarkan kutipan di atas menjelaskan tentang larangan-larangan yang tidak patut dikerjakannya atau dilaksanakan oleh seseorang yang pada akhirnya akan menemui jalan buntu. Lontar Tutur Parakriya menguatkan tentang peranan etik dalam usaha menuju alam kebebasan, sebab perbuatan-perbuatan atau tata cara yang berpatokan pada etika dapat mewujudkan ciri khas dari pelaksanaan bathin yang suci. Oleh karena itu untuk berbuat etika oleh didukung oleh kesucian bathin, sehingga tindakan dalam tingkah laku itu terjadi dengan kesungguhannya.

Selain itu juga untuk dapat memahami ajaran Catur Pāramitha tersebut, di bawah ini di sajikan beberapa bentuk larangan-larangan 
yang pantang dilaksanakan oleh umat manuisa, sebagai berikut : 1) untuk dapat berbuat Maitri, maka jangan melakukan/ berbuat bencana yang bersifat maut (anta kabhaya) atau jangan membenci, 2) untuk dapat berbuat Karuna, maka pantang melakukan perbuatan yang menyebabkan terjadinya penderitaan, tersiksa, kesengsaraan, atau jangan bengis, 3) untuk dapat berbuat Mudita, maka jangan melakukan perbuatan yang dapat menyebabkan orang lain susah, atau jangan memiliki rasa irihati kepada orang lain, 4) untuk dapat berbuat Upekśā, maka pantang menghina orang lain. Memandang rendah orang lain, menindas orang lain, atau selalu dapat berusaha mengendalikan dorongan hawa nafsu jahat.

Agama mengajarkan kepada umatnya untuk percaya dan menyembah Ida Sang Hyang Widhi Wasal Tuhan Yang Maha Esa adalah satu-satunya jalan bagi umat manusia untuk mencapai tujuan agama yaitu kesempurnaan hidup rohani maupun jasmani. Tercapainya kesempurnaan tersebut maka pikiran kita harus mengarah pada kesucian atau hal-hal utama dan mulia. Sehubungan dengan hal di atas, Lontar Tutur Parakriya menyebutkan sebagai berikut :

Manah suniata, cita sunyata, yatat suniata, ika kabeh ya ta kapangguh ikang parama niskala denta, ndia lwirnia jnyana sunia nihan.

(Transkripsi Lontar Tutur Parakriya, 12b).

\section{Terjemahan:}

pikiran utama, maksud utama, semuanya itu utama (sunya), jalan pikiran yang demikian itu, dapat mencapai kesukaan lahir dan bathin olehnya.
Berdasarkan kutipan di atas menjelaskan bahwa moksa adalah dimana perasaan itu dilukiskan sebagai tingkat keadaan dimana rasa "akunya" tidak dirasakan lagi adanya, demikian juga tidak adanya rasa senang atau duka melainkan disadari sebagai satu tingkat kebahagiaan yang paling tinggi yang berlandaskan pada ajaran dharma. Maksud dan tujuan menjalankan dharma selama hidup sebagai manusia karena hanya sebagai manusia itulah seseorang akan dapat berbuat baik karena manusia dapat membedakan hal yang baik dari yang buruk. Hidup ini dianggap sebagai satu jembatan dan keberhasilan seseorang memanfaatkan jembatan ini untuk dapat ia masuk ke surga tergantung cara mengaplikasikan dharma. Pernyataan ini mengandung arti perintah dengan segala konsekwensinya, yaitu tidak dilaksanakan penderitaan akibatnya, dan sebaliknya dipatuhi, surga pahalanya.

Mendalami Lontar Tutur Parakriya adalah suatu pedoman hidup di dalam menunjang hidup dan kehidupan asalnya dari ciptaan Ida Sang Hyang Widhi Wasa/ Tuhan Yang Maha Esa, dimana hidup sebagai mahkluk utama tidak bisa lepas dari pedoman dasar hidup manusia yakni ; a) bekerja artinya sebagai manusia harus berkerja untuk mencukupi kebutuhan hidupnya berlandaskan dharma sebagai ramburambu hidup dalam kehidupan ini, b) belajar dharma atau tattwa artinya sebagai manusia selalu belajar karena belajar tidak akan pernah berakhir selama manusia hidup sehingga bisa berwiweka, melaksanakan perbuatan baik (śubhakarma) dan menghindari perbuatan kurang baik (aśubhakarma), c) mengabdi dan berbhakti artinya sebagai manusia harus berbhakti kepada Ida Sang Hyang Widhi Wasal 
Tuhan Yang Maha Esa, leluhur/ orang tua, dan sesama sehingga terjadi keharmonisan, keserasian, keseimbangan dalam kehidupan agar tercipta suasana yang aman, tentram, damai, d) bermasyarakat atau bergaul yang positif, artinya pergaulan menentukan segalanya, salah bergaul misalnya bergaul dengan penjahat, akan tertular tabiat tersebut, untuk itu pilih-pilihlah dalam pergaulan.

Menguasai ajaran-ajaran yang terdapat dalam Lontar Tutur Parakriya, maka hendaknya memiliki sifat-sifat sattwam dan mengendalikan sifat rajas dan tamas, seperti: tabah di dalam menghadapi cobaan-cobaan hidup yang penuh dengan suka dan duka, tekun mengerjakan suatu pekerjaan yang bermanfaat bagi dirinya dan orang banyak tanpa memperhitungkan untung dan rugi, selalu melaksanakan danapunya kepada orang lain yang memerlukannya, baik berupa materi maupun spiritual, selalu taat mempelajari ilmu kesucian dan bhakti serta sifat-sifat mulia lainnya yang sangat bermanfaat bagi dirinya maupun orang banyak.

\section{Simpulan}

Ajaran tattwa yaitu moksa adalah dapat tercapai bila seseorang di dalam hidup dan kehidupannya selalu dilandasi dengan perbuatan yang digolongkan pada sifat kedewataan yakni perbuatan yang selalu menonjolkan sifat sattwam. Ajaran etika, yaitu dapat menuntun seseorang di dalam kehidupannya untuk selalu berbuat yang luhur, melaksanakan kebajikan atas dasar Catur Pāramitha, yaitu: 1) untuk dapat berbuat Metri, maka jangan melakukan/ berbuat bencana yang bersifat maut (anta kabhaya) atau jangan membenci,
2) untuk dapat berbuat Karuna, maka pantang melakukan perbuatan yang menyebabkan terjadinya penderitaan, tersiksa, kesengsaraan, atau jangan bengis, 3) untuk dapat berbuat Mudita, maka jangan melakukan perbuatan yang dapat menyebabkan orang lain susah, atau jangan memiliki rasa irihati kepada orang lain, 4) untuk dapat berbuat Upekśā, maka pantang menghina orang lain. Memandang rendah orang lain, menindas orang lain, atau selalu dapat berusaha mengendalikan dorongan hawa nafsu jahat. Tuntunan susila yang mulia dan luhur itu harus diaplikasikan sehingga terjadi keharmonisan antar sesama dan selalu berbuat Śubhakarma dan menjauhi perbuatan yang Aśubhakarma karena jalan itulah sesuai dengan tentunya ajaran Agama Hindu.

\section{DAFTAR PUSTAKA}

LONTAR :Transkrip Lontar Tutur Para Kriya, Koleksi Gedong Kirtya Singaraja No. IIIB.601/1.

Kadjeng, I Nyoman. 1997. Sarasamuccaya. Surabaya: Paramita

Kemenuh, Ida Pedanda Putra, 1983, Geguritan Dharma Prawretti, Singaraja, Kantor Departemen Kabupaten Buleleng.

Oka, Agung I Gusti, 1992, Slokantara, Jakarta: Hanuman Sakti.

Mantra, Ida Bagus, 1997, Tata Susila Hindu Dharma, Denpasar: Upada Sastra.

Proyek Penyuluhan Agama dan Penerbitan Buku Agama, 1988, Upadesa tentang Ajaran-ajaran Agama Hindu, tp. 
Pudja, G. 1999. Bhagawadgita. Surabaya: Paramita.

Sura, I Gde, Ida Bagus Kade Sindhu, Ida Bagus Gde Agastya, 1981, Pengantar Tattwa Darsana Filsafat Jilid I untuk Kelas I PGAH Negeri Denpasar.

Sura, I Gede, 2001, Pengendalian Diri dan Etika Dalam Ajaran Agama Hindu, Jakarta: Hanuman Sakti.

Titib, I Made, 1994, Untaian Ratna Sari Upanisad, Denpasar: Yayasan Dharma Naradha.

Zoetmulder, PJ, 1994, Kalangwan Sastra Jawa Kuno Selayang Pandang, Penerbit Djambatan. 